\title{
PHARMACOGENETIC VARIATIONS RELATED TO CLOPIDOGREL RESISTANCE AND ITS CLINICAL IMPLICATIONS: AN ISSUE WHICH REMAINS LARGELY UNADDRESSED
}

\author{
SABREEN BASHIR*, POORNIMA R
}

Department of Pharmacology, JSS Medical College, JSS University, Mysore, Karnataka, India. Email: sabreenbhat.sb@gmail.com

Received: 02 June 2016, Revised and Accepted: 20 June 2016

\section{ABSTRACT}

Objectives: Antiplatelet therapy with either clopidogrel alone or in combination with aspirin is the mainstay prophylactic drug therapy following percutaneous coronary intervention and long-term prevention of cardiovascular and cerebrovascular events. Non-responders/semi-responders to clopidogrel are reported to have increased incidences of adverse outcomes like recurrent ischemic attacks. Variability in response to clopidogrel is more common among Asians, and it is as high as $70 \%$ in some of the Asian communities. Researchers attribute inter-individual variations in response to clopidogrel to various pharmacogenetic determinants. Polymorphisms of multidrug resistance protein 1, CYP2C19 and its alleles, P2Y $_{1}$, and P2Y ${ }_{12}$ adenosine diphosphate (ADP) receptor are concluded to be specific to clopidogrel resistance in Indian population.

Methods: A thorough literature search was done use different keywords such as clopidogrel resistance, pharmacogenomics, pharmacogenetic variability, and ethnic variability from database sources such as Google Scholar, Medline, PubMed Central, and Scopus.

Results and Conclusion: Literature revealed a disparity between various pharmacogenetic determinants of clopidogrel resistance, particularly in the Asian population. Few studies suggest that there is no significant association between clopidogrel response variability and ADP receptor P2Y and P2Y 12 gene polymorphisms. Variation in the cytochrome P450 2C19 (CYP2C19) gene coding for the CYP2C19 enzyme, involved in metabolism and conversion of the clopidogrel to active metabolites is considered one of the major determinants of clopidogrel resistance in some populations. Pooled data from various studies suggest that variability in clopidogrel response cannot be attributed to a single gene polymorphism and is thought to be multifactorial. However, disparity in the data related to the specific gene polymorphisms responsible for the encountered clopidogrel resistance necessitates the further evaluation of genome.

Keywords: Clopidogrel, Clopidogrel resistance, Single gene polymorphisms, Inter-individual variability.

(C) 2016 The Authors. Published by Innovare Academic Sciences Pvt Ltd. This is an open access article under the CC BY license (http://creativecommons org/licenses/by/4. 0/) DOI: http://dx.doi.org/10.22159/ajpcr.2016.v9i5.13210

\section{INTRODUCTION}

Clopidogrel is an oral thienopyridine derivative which inhibits platelet activation and aggregation by irreversibly blocking the platelet adenosine diphosphate (ADP) $\mathrm{P}_{2} \mathrm{Y}_{12}$ receptor. Platelet $\mathrm{P}_{2} \mathrm{Y}_{12}$ receptor inhibitors are the Class IA recommended drugs in patients with acute coronary syndromes (ACS) and undergoing percutaneous coronary intervention $(\mathrm{PCI})$, of which clopidogrel is the highest utilized drug worldwide. Clopidogrel is a prodrug that requires biotransformation to an active metabolite. Catalyzed by the enzyme CYP2C19, the active metabolite irreversibly blocks the $\mathrm{P}_{2} \mathrm{Y}_{12}$ component of ADP receptors on the platelet surface, which prevents activation of the glycoprotein IIb/IIIa receptor complex, thereby reducing platelet aggregation [1] However, despite being the most widely prescribed drug along with aspirin as the dual antiplatelet therapy, there is a significant evidence of adverse clinical outcomes such as recurrent atherothrombotic events in patients on clopidogrel therapy. Variability in response to clopidogrel is more common among Asians, and it is as high as 70\% in some of the Asian communities [2].

Clopidogrel absorption and metabolism is complex and involves efflux pumps and enzymes that have polymorphic genes. Single nucleotide polymorphism (SNP) in the CYP2C19*2, ABCB1/MDR1 gene, $\mathrm{P}_{2} \mathrm{Y}_{1}$ and $\mathrm{P}_{12} \mathrm{Y}_{12} \mathrm{ADP}$ receptor are considered to be responsible for clopidogrel non-responsiveness [3]. Variation in the (CYP2C19) gene coding for the CYP2C19 enzyme, involved in the conversion of the clopidogrel to active metabolites is considered one of the major determinants of clopidogrel resistance in some populations.

Patients with high on-treatment platelet reactivity (HPR) or genetic variations, such as cytochrome P450 (CYP) 2C19 loss-of-function alleles, have an increased risk of ischemic events, particularly stent thrombosis. Heterogeneity in response to clopidogrel suggests the need for pharmacogenetic testing with consideration of alternative antiplatelet agents in non-responders. Ethnic groups, with a higher frequency of SNPs responsible for clopidogrel resistance, may be benefited from prior genetic testing. The current review summarizes the genetic polymorphisms affecting clopidogrel resistance, variability in response in different ethnic groups, especially the Asian population and related adverse clinical outcomes.

\section{Genetic determinants of response to clopidogrel}

The relationship between CYP2C19*2 gene polymorphism and clopidogrel resistance reflected by platelet function assays has been studied extensively in the past several years. A meta-analysis conducted on eight studies with a total of 2,331 subjects, including 1,066 patients with clopidogrel resistance and 1,265 patients without clopidogrel resistance suggested that $\mathrm{CYP} 2 \mathrm{C} 19 * 2$ gene polymorphism may be associated with clopidogrel resistance [4]. Recently, studies have shown that CYP2C $19 * 3, * 4, * 5, * 6, * 7$, and $* 8$ alleles may also affect clopidogrel metabolism in the same way as CYP2C19*2; however, their frequency in population is negligible as compared to CYP2C19*2 allele [5]. A study conducted on 72 patients of Indian Origin suggested PLA1/A2 gene variation in addition to CYP2C19*2 in clopidogrel semi-responders [6]. Classified as extrinsic mechanisms and intrinsic mechanisms for clopidogrel resistance, the extrinsic may be the possibility of clopidogrel underdosing in patients undergoing stenting or with ACS, and drug-drug interactions involving CYP3A4. Intrinsic mechanisms include genetic polymorphisms of the P2Y12 receptor and of the CYP3As, accrued release of ADP, or upregulation of other platelet activation pathways [7].

However, a study conducted on 100 patients of coronary artery disease (CAD) who were on the maintenance dose of clopidogrel (75mg OD) 
with or without aspirin out of which 10 received loading dose (300mg) before PCI, concluded that clopidogrel resistance was not associated with ADP receptor P2Y1 and P2Y12 gene polymorphisms [8].

A large scale genetic epidemiology study, which enrolled 2128 IndoEuropeans residing in North India, were studied for the presence of variants associated with pharmacogenetics of clopidogrel. This study revealed that Indians had a higher allele frequency for variants in the $C Y P 2 C 9^{*} 2, C Y P 2 C 9^{*} 3$, and $P 2 R Y 1$ genes, whereas lower frequency for the $A B C B 1, C Y P 1 A 2, C Y P 2 C 19^{*} 2 C, C Y P 3 A 5$, and PON1 genes compared with the global population [9].

Pooled data from various studies suggest that variability in clopidogrel response cannot be attributed to a single gene polymorphism and is thought to be multifactorial.

HPR: A significant contributor to clopidogrel semi/nonrespondence

Studies of platelet function testing (PFT) have shown variability in the pharmacodynamic response to clopidogrel. Patients with High ontreatment platelet reactivity (HPR) have an increased risk of ischemic events, particularly stent thrombosis.

Similarly, patients with low on-treatment platelet reactivity or patients with genetic variants associated with increased clopidogrel metabolism have been associated with bleeding risk [10].

Although small studies have provided evidence that treatment adjustments based on PFT results may improve clinical outcomes, the available randomized controlled trials showed no benefit of modifying antiplatelet treatment based on PFT [11].

The Gauging Responsiveness with a VerifyNow Assay-Impact on Thrombosis and Safety (GRAVITAS) trial was the first large-scale clinical trial to test the clinical impact of high-versus standard-dose clopidogrel in HPR patients identified by the verify now P2Y12 assay. The trial was conducted in patients $\left(\mathrm{n}^{1} / 42,214\right)$ undergoing PCI with drug-eluting stents (DES); many were undergoing complex interventions. However, the trial failed to observe any benefit of intensified antiplatelet treatment, showing identical 6 months ischemic endpoints in the 2 treatment arms (2.3\% vs. $2.3 \%$ ). Contrary to GRAVITAS, high event rates were observed in the responsiveness to clopidogrel and stent thrombosis 2-ACS study and it showing a $14.6 \%$ event rate at 2 years among HPR patients. testing platelet reactivity in patients undergoing elective stent placement on clopidogrel to guide alternative therapy with prasugrel trial, in which HPR patients with stable CAD undergoing elective PCI with DES were randomized to treatment with prasugrel versus clopidogrel. However, after randomizing 423 HPR patients, the trial was interrupted for futility as only a single ischemic event had occurred. However, the results of these trials cannot be fully relied on owing due some inherent characteristics of the study design and randomization, one of it being that randomizing before PCI could have potentially affected peri-procedural event rates [12].

\section{Pharmacogenetic variability leading to adverse cardiovascular events}

Studies, such as French registry of acute ST-elevation and non-STelevation myocardial infarction study, designed to evaluate whether previously identified polymorphisms of genes modulating clopidogrel absorption (ABCB1), metabolic activation (CYP3A5 and CYP2C19), and biologic activity (P2RY12 and ITGB3) were associated with death or ischemic events during a 1-year follow-up in patients receiving clopidogrel after acute myocardial infarction concluded that genetic variants in CYP2C19 that result in loss of function were associated with an increase in the risk of death, myocardial infarction, or stroke, especially among patients undergoing PCI [13].

Another study, trial to assess improvement in therapeutic outcomes by optimizing platelet inhibition with prasugrel-thrombolysis in myocardial infarction 38 study demonstrated a greater than 3 -fold increase in the risk of adverse cardiovascular events among patients undergoing PCI who were homozygous or heterozygous for any of the CYP2C19 alleles known to result in a nonfunctional protein (CYP2C19*2*3,*4, and $* 5$ ), as compared with patients who had the wild-type CYP2C19*1 allele [14].

Assessment of dual antiplatelet therapy with DES trial, the largest prospective multicenter observational study of unselected clopidogreltreated patients $(n=8.575)$ undergoing DES implantation in whom PFT with the VerifyNowP2Y12 assay was performed. The trial observed 39 definite/probable stent thromboses at 30 days $(0.46 \%)$ occurring in patients with ACS [15]

\section{CONCLUSION}

The significant adverse clinical outcomes resulting from the variability in the response to clopidogrel, secondary to the genetic variations in the individual mandates the need for genetic testing before the initiation of clopidogrel therapy more so in individuals of Asian origin. Antiplatelet therapy with alternate agents such as prasugrel and another novel drug ticagrelor an antagonist of the $\mathrm{P}_{2} \mathrm{Y}_{12}$ receptor may be considered in clopidogrel non-responders. Moreover, the drug does not need hepatic activation, which might work better for patients with genetic variants regarding the enzyme CYP2C19 [16].

Ethnic groups, with a higher frequency of SNPs responsible for clopidogrel resistance, may be benefited from prior genetic testing. However, before incorporating this in the standard guidelines, it is necessary to further study the genetic determinants to fully elucidate the pharmacogenomics of clopidogrel resistance. Genetic testing and tailored therapy on individualized basis also await results from largescale clinical trials for recommendations on alternate treatments for non-responders.

\section{REFERENCES}

1. Mega JL, Close SL, Wiviott SD, Shen L, Hockett RD, Brandt JT, et al Cytochrome p-450 polymorphisms and response to clopidogrel. N Engl J Med 2009;360(4):354-62.

2. Hasan MS, Basri HB, Hin LP, Stanslas J. Genetic polymorphisms and drug interactions leading to clopidogrel resistance: Why the Asian population requires special attention. Int J Neurosci 2013;123(3):143-54

3. Shalia KK, Shah VK, Pawar P, Divekar SS, Payannavar S. Polymorphisms of MDR1, CYP2C19 and P2Y12 genes in Indian population: Effects on clopidogrel response. Indian Heart J 2013;65(2):158-67.

4. Hou X, Shi J, Sun H. Gene polymorphism of cytochrome P450 2C19*2 and clopidogrel resistance reflected by platelet function assays: A metaanalysis. Eur J Clin Pharmacol 2014;70(9):1041-7.

5. Gladding P, Webster M, Zeng I, Farrell H, Stewart J, Ruygrok P, et al. The pharmacogenetics and pharmacodynamics of clopidogrel response: An analysis from the PRINC (Plavix Response in Coronary Intervention) trial. JACC Cardiovasc Int 2008;1(6):620-7.

6. Arya V, Mahajan P, Saraf A, Mohanty A, Sawhney JP, Bhargava M. Association of CYP2C19, CYP3A5 and GPIIb/IIIa gene polymorphisms with Aspirin and clopidogrel resistance in a cohort of Indian patients with Coronary artery disezase. Int J Lab Hematol 2015;37(6):809-18.

7. Nguyen TA, Diodati JG, Pharand C. Resistance to clopidogrel: A review of the evidence. J Am Coll Cardiol 2005 19;45(8):1157-64

8. Kar R, Meena A, Yadav BK, Yadav R, Kar SS, Saxena R. Clopidogrel resistance in North Indian patients of coronary artery disease and lack of its association with platelet ADP receptors P2Y1 and P2Y12 gene polymorphisms. Platelets 2013;24(4):297-302

9. Anil KG, Nazir MK, Analabha B, Nikhil T, Vinod S, Grover S, et al. Pharmacogenetic landscape in north Indian population suggests distinct interpopulation differences in allele frequencies. Pharmacogenomics 2014;15(5):643-53.

10. Bonello L, Tantry US, Marcucci R, Aradi D, Price MJ, Jeong YH, et al. For the working group on high on-treatment platelet reactivity. Consensus and future directions on the definition of high on-treatment platelet reactivity to adenosine diphosphate. J Am Coll Cardiol 2010;56:919-33.

11. Gross L, Aradi D, Sibbing D. Platelet Function Testing in Patients on Antiplatelet Medications. Semin Thromb Hemost 2016;42(3):306-20.

12. Angiolillo DJ, Ferreiro JL, Price MJ, Kirtane AJ, Stone GW. Platelet 
function and genetic testing. Am Coll Cardiol 2013;62 17 Suppl: S21-31.

13. Simon T, Verstuyft C, Mary-Krause M, Quteineh L, Drouet E, Méneveau $\mathrm{N}$, et al. Genetic determinants of response to clopidogrel and cardiovascular events. N Engl J Med 2009;360(4):363-75.

14. Feher G, Feher A, Pusch G, Koltai K, Tibold A, Gasztonyi B, et al. Clinical importance of aspirin and clopidogrel resistance. World $\mathrm{J}$ Cardiol 2010;2(7):171-86.

15. Kirtane AJ. The concept of a therapeutic window of optimal antiplatelet activity: Insights from ADAPT-DES. Abstract Presented at: $62^{\text {nd }}$ Annua American College of Cardiology Scientific sessions, March 9-11, San Francisco, CA; 2013.

16. Tantry US, Bliden KP, Wei C, Storey RF, Armstrong M, Butler K, et al. First analysis of the relation between CYP2C19 genotype and pharmacodynamics in patients treated with ticagrelor versus clopidogrel: The ONSET/OFFSET and RESPOND genotype studies. Circ Cardiovasc Genet 2010;3(6):556-66. 